\title{
Evaluation of the QuEChERS Method and Gas Chromatography- Mass Spectrometry for the Analysis Pesticide Residues in Water and Sediment
}

\author{
S. H. G. Brondi • A. N. de Macedo • \\ G. H. L. Vicente $\cdot$ A. R. A. Nogueira
}

Received: 5 August 2010/Accepted: 2 December 2010/Published online: 17 December 2010

(C) The Author(s) 2010. This article is published with open access at Springerlink.com

\begin{abstract}
A method for the determination of pesticide residues in water and sediment was developed using the QuEChERS method followed by gas chromatography - mass spectrometry. The method was validated in terms of accuracy, specificity, linearity, detection and quantification limits. The recovery percentages obtained for the pesticides in water at different concentrations ranged from 63 to $116 \%$, with relative standard deviations below $12 \%$. The corresponding results from the sediment ranged from 48 to $115 \%$ with relative standard deviations below $16 \%$. The limits of detection for the pesticides in water and sediment were below $0.003 \mathrm{mg} \mathrm{L}^{-1}$ and $0.02 \mathrm{mg} \mathrm{kg}^{-1}$, respectively.
\end{abstract}

Keywords Pesticides - QuEChERS method - Water · Sediment

In recent years there has been growing environmental concern, especially regarding the use and discharge of toxic substances. Hence there is a growing need to monitor organic micropollutants in environmental studies and to control the quality of food. Pollution has been very damaging to aquatic ecosystems, and may consist of agricultural, urban, and industrial wastes containing contaminants that have proven to be very damaging to aquatic habitats and species (EPA 2009).

S. H. G. Brondi $(\bowtie) \cdot$ A. R. A. Nogueira

Embrapa Pecuária Sudeste, Rodovia Washington Luiz,

km 234, São Carlos Zip Code: 13560-970, Brazil

e-mail: shgb@uol.com.br

A. N. de Macedo - G. H. L. Vicente

Universidade de São Paulo, Avenida do Trabalhador

São-carlense, 400, São Carlos 13566-590, Brazil
Contamination of water resources by pesticide residues is one of the major challenges for the preservation and sustainability of the environment (Kustera et al. 2009). However, these chemicals must be used properly, respecting the law, the environment and human health, since they are toxic and can cause contamination (Sanches et al. 2003).

The determination of the residues of pesticides in food and environmental samples is very important due to the riscs that these compounds offer to human health, besides their persistence in the environment and their tendency to bioaccumulation (Prestes et al. 2009). The aquatic environment is one of the most affected by pesticide residues. It is important to monitor the water quality, especially in regions close to agricultural areas and in places where there are primary sources of drinking water (Sanches et al. 2003). These pollutants present in water resources at low concentrations can affect ecosystems and impact drinking water supplies (Gervais et al. 2008).

The analysis of sediments should be included in environmental studies because they are the result of the integration of all processes (biological, physical and chemical) that occur in an aquatic ecosystem, influencing the metabolism of the whole system. Sediments are very different in composition, forms and processes and can provide valuable information about water quality (Tundisi 2003). In relation of reservoirs, sediments are considered to be compartments of accumulation of pollutants, brought by the water column, that have their origin in the different uses of soil of the drainage areas' basin (Bonai et al. 2009).

Materials carried from the terrestrial environment can affect water bodies, among then sand, clay, contaminants, fertilizers, etc. If they are insoluble or poorly soluble and denser than water, they will be deposited as sediments, remaining there or being released into the water column 
under certain circumstances and in any event potentially affecting the aquatic food chain.

Trace analysis of organic contaminants such as pesticides in food, biotic and environmental samples typically consist of following consecutive steps: isolation of analytes from the sample matrix, removal of bulk co-extracts from crude extract, identification and quantification of target analytes and examination the make sure there have been no false positive results (Hajslová and Zrostlíková 2003).

Many innovations have occurred in analytical methods for the extraction of organic compounds from different matrices (e.g. food, biological, and environmental) that reduce the analysis time, minimize the number of analytical steps, use fewer reagents in smaller amounts and provide high recovery. Recently, Anastassiades et al. (2003) developed an approach called "quick, easy, cheap, effective, rugged, and safe" (QuEChERS), which involves extraction with $\mathrm{MeCN}$ partitioned from the aqueous matrix using anhydrous $\mathrm{MgSO}_{4}$ and $\mathrm{NaCl}$ followed by a dispersive-SPE cleanup with $\mathrm{MgSO}_{4}$ and primary secondary amine (PSA). The QuEChERS method commonly uses GC-MS and LC-MS/MS to cover the wide range of pesticides for analysis (Cunha et al. 2007).

Most applications in the analysis of pesticide residues are based on chromatographic determination, both by gas chromatography (GC) and high performance liquid chromatography (HPLC), but it is often necessary to use other techniques such as mass spectrometry to identify the analytes separated by the chromatographic technique. GC-MS has become a standard laboratory instrument and can provide qualitative and quantitative information for essentially any GC-amenable analyte in a single injection. The most common MS technique uses a very rugged and practical quadrupole design, along with ionization is by electron impact (EI) (Lehotay 2005).

Method validation is an important requirement in the practice of chemical analysis. The analyst must generate information to show that a method intended for these purposes is capable of providing adequate specificity, accuracy and precision, at relevant analyte concentrations and in appropriate matrices (Hill and Reynolds 1999).

The aim of this study was to evaluate the QuEChERS method in combination with gas chromatography-mass spectrometry (GC-MS) for the determination of atrazine, fipronil and endosulfan in sediment and water samples.

\section{Materials and Methods}

The standard pesticides were obtained from Sigma-Aldrich (Germany) with $96.7 \%$ purity. The stock and working solutions were prepared in MeCN solvent, HPLC grade, obtained from Mallinckrodt (USA). Dispersive - SPE sorbents included PSA, obtained from Varian (USA), and $\mathrm{C} 18(50 \mu \mathrm{m})$, obtained from J.T.Baker (USA). $\mathrm{NaCl}$ was obtained from Synth (Brazil) and $\mathrm{MgSO}_{4}$ from Mallinckrodt Baker (USA). The water and sediment samples used for the blank and fortified studies were obtained from an uncontaminated reservoir.

In this study QuEChERS method was applied according to Anastassiades et al. (2003) and Lehotay et al. (2005). In developing the method, the analytical procedure consisted of the following steps: (a) placing a sample of $10 \mathrm{~g}$ of water or dry sediment into a centrifuge tube; (b) adding atrazine, fipronil and endosulfan in the required concentrations; (c) adding $10 \mathrm{~mL}$ of $\mathrm{MeCN}, 4 \mathrm{~g}$ of $\mathrm{MgSO}_{4}$ and $1 \mathrm{~g}$ of $\mathrm{NaCl}$ in each tube, and centrifuging it at 3,000 rpm for $1 \mathrm{~min}$; (d) transferring $5 \mathrm{~mL}$ of $\mathrm{MeCN}$ extract to a commercial SPE cartridge containing $330 \mathrm{mg}$ PSA, $330 \mathrm{mg} \mathrm{C} 18$ and a $1 \mathrm{~cm}$ layer of $\mathrm{MgSO}_{4}$ activated with $3 \mathrm{~mL}$ of $\mathrm{MeCN}$. Then, in the column SPE, (e) the extract was passed and collected; (f) $1.0 \mathrm{~mL}$ of the extract was transferred to an autosampler vial (Shimadzu AOC-20i autoinjector - Kyoto, Japan) for analysis by GC-MS. The volume analyzed was $1 \mu \mathrm{L}$.

The analyte concentrations were determined through gas chromatography combined with mass spectrometry using a QP 2010 GC-MS from Shimadzu, equipped with a mass selective detector (MSD) and a 30-m DB-5 capillary column, with an internal diameter of $0.25 \mathrm{~mm}$ and film thickness of $0.1 \mu \mathrm{m}$.

The analytical conditions were injector temperature: $250^{\circ} \mathrm{C}$, interface temperature: $250^{\circ} \mathrm{C}$, the carrier gas with a flow rate of $0.75 \mathrm{~mL} \mathrm{~min}{ }^{-1}$. The injections were done in the splitless mode with an oven temperature program of $120^{\circ} \mathrm{C}$ for $3 \mathrm{~min}$, $18^{\circ} \mathrm{C} \min ^{-1}-220^{\circ} \mathrm{C}$ and $20^{\circ} \mathrm{C} \mathrm{min}^{-1}-270^{\circ} \mathrm{C}$ for $5 \mathrm{~min}$.

The mass spectrometer was operated initially in the SCAN mode, sweeping between $\mathrm{m} / \mathrm{z} 45$ and $\mathrm{m} / \mathrm{z} 475$, which allowed the detection of analytes in solvent to the limit $1.0 \mathrm{mg} \mathrm{L}^{-1}$. Lower concentration could be detected in the SIM mode by selecting the characteristic ions $(\mathrm{m} / \mathrm{z})$ atrazine: 173, 200, 215; fipronil: 215, 351, 367; $\alpha$-endosulfan: 161, 195, 241; $\beta$-endosulfan: 195, 239, 281.

To check the credibility of the data in the quantitative analyses, analytical validation of the method was performed. The factors considered in the validation included recovery, precision (relative standard deviation), determination coefficient $\left(\mathrm{R}^{2}\right)$, linearity, detection (LOD) and quantification (LOQ) limits (Lanças 2004; Hill and Reynolds 1999; Ribani et al. 2004; Aysal et al. 2007).

\section{Results and Discussion}

Pesticide residues were determined by GC-MS-SIM in order to obtain the separation of atrazine, fipronil and endosulfan $(\alpha, \beta)$ with adequate sensitivity. 

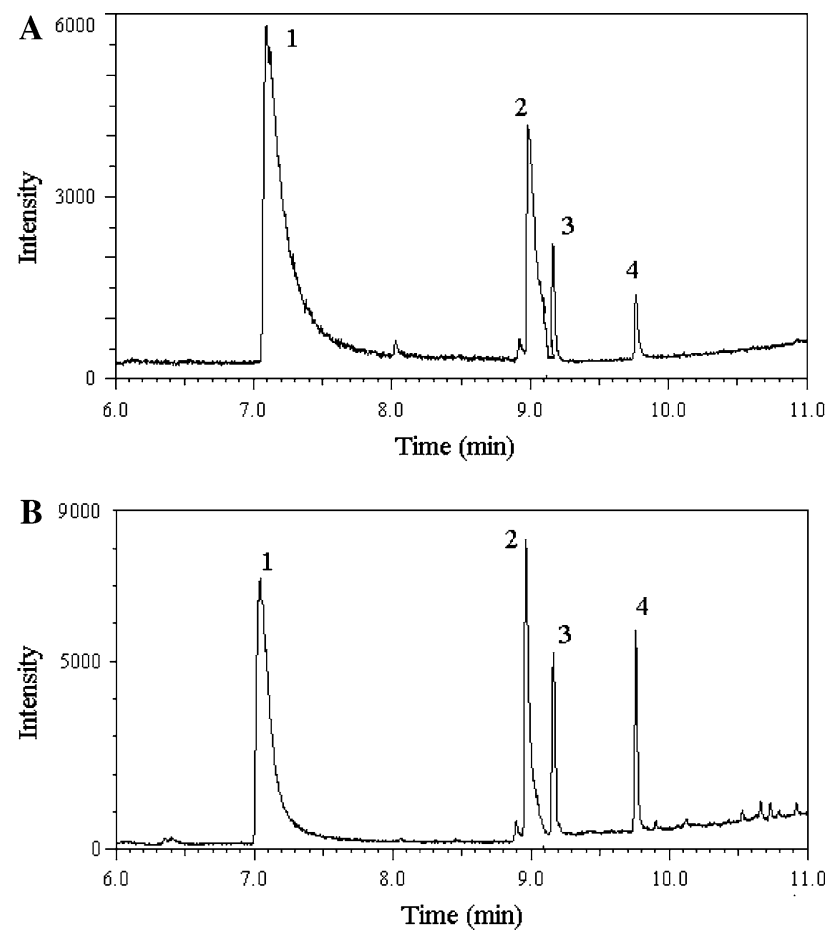

Fig. 1 GC-MS chromatogram of a mixture of pesticides obtained after QuEChERS method was applied, in the concentration of $0.1 \mathrm{mg} \mathrm{kg}^{-1}$ in sediment (a) and $0.1 \mathrm{mg} \mathrm{L}^{-1}$ in water (b) samples. $1=$ atrazine $(\operatorname{tr}=7.15 \mathrm{~min}) ; 2=$ fipronil $(\operatorname{tr}=9.00 \mathrm{~min}) ; 3=$ $\alpha$-endosulfan $(\operatorname{tr}=9.17 \mathrm{~min}) ; 4=\beta$-endosulfan $(\operatorname{tr}=9.75 \mathrm{~min})$

The QuEChERS method was applied to sample preparation in this study, because it has several advantages over most of the traditional extraction techniques, according to Lehotay (2005): high recoveries for a wide polarity and volatility range of pesticides; very accurate results; low solvent usage and waste; and high sample throughput. Besides these advantages, a single person can perform the method without much training or technical skill, the method is quite rugged, relatively inexpensive and few materials and glassware are needed. This method is nowadays the most applied extraction method for the determination of pesticide residues in food samples, providing acceptable recoveries for acidic, neutral and basic pesticides (Prestes et al. 2009), such as fruits and vegetables
(Anastassiades et al. 2003; Aysal et al. 2007), rice (Koesukwiwat et al. 2008), milk, eggs and avocados (Lehotay et al. 2005), olives and olive oil (Cunha et al. 2007), and soil (Lesueur et al. 2008), but to our knowledge this is the first application of the method to sediments.

The representative chromatograms obtained from extracts of pesticide-fortified in sediment $\left(0.1 \mathrm{mg} \mathrm{kg}^{-1}\right)$ and in water $\left(0.1 \mathrm{mg} \mathrm{L}^{-1}\right)$ after the QuEChERS method was applied are shown in Fig. 1. The QuEChERS method resulted in extracts that contained the target analyte, with high recovery, and free from interferences in the region of the chromatogram near the retention time of the pesticides.

Validation is an essential requirement to ensure quality and reliability of the results for all analytical applications (Paschoal et al. 2008).

Accuracy: We calculated the percentage of recovery and reproducibility, expressed as relative standard deviations (RSD) of the proposed method. The experiments were performed by spiking the water and sediment samples with the pesticides being studied. The recoveries obtained for all pesticides in water at different concentrations ranged from $63 \%$ to $116 \%$, with relative standard deviations below $12 \%$, and in the sediment ranged from $48 \%$ to $115 \%$, with relative standard deviations below $16 \%$ (Table 1). These values are within the range stipulated by the U.S. Environmental Protection Agency (Tolosa et al. 1996), which is from $70 \%$ to $130 \%$, with relative standard deviations below $30 \%$, with the exception of endosulfan in water at a concentration below $0.05 \mathrm{mg} \mathrm{L}^{-1}$ and atrazine in sediment at a concentration of $0.02 \mathrm{mg} \mathrm{kg}^{-1}$.

Specificity: The specificity of the method was determined by analyzing blank water and sediment samples. The absence of background peaks, above a signal-to-noise ratio of 3 , at the retention times of the target pesticides, showed that no interferences occurred.

Linearity: An external calibration plot was constructed in triplicate $(n=3)$ for analysis of blank water and sediment samples fortified by the addition of standard solutions of the pesticides, at levels of $0.01,0.02,0.05,0.10,0.20$ and $0.5 \mathrm{mg} \mathrm{L}^{-1}$ and $\mathrm{mg} \mathrm{kg}^{-1}$, respectively. The response for all pesticides was linear in the concentration range

Table 1 Recovery and precision (RSD) from fortified water and sediment samples using the QuEChERS method and GC-MS

\begin{tabular}{|c|c|c|c|c|c|c|}
\hline \multirow[t]{3}{*}{ Pesticides } & \multicolumn{6}{|c|}{ Recovery $(\%) \pm \operatorname{RSD}(\%)$} \\
\hline & \multicolumn{3}{|c|}{ Water $\left(\mathrm{mg} \mathrm{L}^{-1}\right)$} & \multicolumn{3}{|c|}{ Sediment $\left(\mathrm{mg} \mathrm{kg}^{-1}\right)$} \\
\hline & 0.01 & 0.05 & 0.5 & 0.02 & 0.05 & 0.5 \\
\hline Atrazine & $111 \pm 8$ & $72 \pm 10$ & $99 \pm 4$ & $48 \pm 15$ & $91 \pm 4$ & $78 \pm 12$ \\
\hline Fipronil & $105 \pm 7$ & $72 \pm 5$ & $116 \pm 8$ & $80 \pm 16$ & $115 \pm 13$ & $101 \pm 7$ \\
\hline$\alpha$-Endosulfan & $64 \pm 11$ & $67 \pm 6$ & $77 \pm 1$ & $80 \pm 2$ & $76 \pm 4$ & $72 \pm 4$ \\
\hline$\beta$-Endosulfan & $63 \pm 12$ & $68 \pm 12$ & $87 \pm 2$ & $69 \pm 9$ & $74 \pm 3$ & $76 \pm 3$ \\
\hline
\end{tabular}


Table 2 Determination coefficient, calibration equation, and values of detection and quantification limits for the investigated pesticides in water and sediment samples

\begin{tabular}{|c|c|c|c|c|c|c|c|c|}
\hline \multirow[t]{2}{*}{ Pesticides } & \multicolumn{4}{|l|}{ Water } & \multicolumn{4}{|l|}{ Sediment } \\
\hline & $\begin{array}{l}\text { Determination } \\
\text { coefficient }\end{array}$ & $\begin{array}{l}\text { Regression equation } \\
(\mathrm{y}=\mathrm{ax} \pm \mathrm{b})\end{array}$ & $\begin{array}{l}\text { LOD } \\
\left(\mathrm{mg} \mathrm{L}^{-1}\right)\end{array}$ & $\begin{array}{l}\text { LOQ } \\
\left(\mathrm{mg} \mathrm{L}^{-1}\right)\end{array}$ & $\begin{array}{l}\text { Determination } \\
\text { coefficient }\end{array}$ & $\begin{array}{l}\text { Regression equation } \\
(y=a x \pm b)\end{array}$ & $\begin{array}{l}\text { LOD } \\
\left(\mathrm{mg} \mathrm{kg}^{-1}\right)\end{array}$ & $\begin{array}{l}\mathrm{LOQ} \\
\left(\mathrm{mg} \mathrm{kg}^{-1}\right)\end{array}$ \\
\hline Atrazine & 0.9964 & $\mathrm{y}=654.9 x-11695.0$ & 0.003 & 0.01 & 0.9853 & $\mathrm{y}=257.2 \mathrm{x}-3463.7$ & 0.02 & 0.05 \\
\hline Fipronil & 0.9970 & $y=179.3 x-2033.7$ & 0.003 & 0.01 & 0.9835 & $y=127.4 x-2048.5$ & 0.003 & 0.01 \\
\hline$\alpha$-Endosulfan & 0.9969 & $y=40.1 x-418.6$ & 0.002 & 0.005 & 0.9993 & $y=38.8 x-9.2$ & 0.003 & 0.01 \\
\hline$\beta$-Endosulfan & 0.9972 & $\mathrm{y}=23.1 \mathrm{x}-209.1$ & 0.002 & 0.005 & 0.9860 & $\mathrm{y}=15.0 \mathrm{x}-276.2$ & 0.003 & 0.01 \\
\hline
\end{tabular}

evaluated, with determination coefficients $>0.996$ and 0.983 for water and sediment, respectively. The determination coefficient value and regression equation for the pesticides are shown in Table 2.

Detection and Quantification Limits: The limits of detection (LOD) and quantification (LOQ) for all pesticides were calculated by considering a value 3 and 10 times the background noise obtained for blank samples, respectively (Lanças 2004). Table 2 presents the LOD and LOQ values for atrazine, fipronil and endosulfan $(\alpha, \beta)$. The low quantification limit achieved - below $0.01 \mathrm{mg} \mathrm{L}^{-1}$ and $0.05 \mathrm{mg} \mathrm{kg}^{-1}$ in water and sediment samples, respectively - allow application of the QuEChERS method followed by GC-MS to monitor pesticide residues in environmental studies.

After validating of the methods for pesticide residue analysis in water and sediment, we applied them to determine the levels of atrazine, fipronil and endosulfan in a river located near a sugarcane plantation. The samples were analyzed by the QuEChERS method, followed by gas chromatography (GC) and mass spectrometry (MS). None of the pesticides analysed were registered, considering the limit of detection of the method for each compound.

Acknowledgments We are grateful to the São Paulo State Research Foundation (FAPESP) and the National Research Council (CNPq) for the financial support given to this study.

Open Access This article is distributed under the terms of the Creative Commons Attribution Noncommercial License which permits any noncommercial use, distribution, and reproduction in any medium, provided the original author(s) and source are credited.

\section{References}

Anastassiades M, Lehotay SJ, Stajnbaher D, Schenck F (2003) Fast and easy multiresidue method employing acetonitrile extraction/ partitioning and "dispersive solid-phase extraction" for the determination of pesticide residues in produce. $\mathrm{J}$ AOAC Int 86:412-431

Aysal P, Ambrus Á, Lehotay SJ, Cannavan A (2007) Validation of an efficient method for the determination of pesticide residues in fruits and vegetables using ethyl acetate for extraction. J Environ Sci Health, Part B 42:481-490

Bonai NC, Souza-Franco GM, Fogolari O, Mocelin DJC, Dal Magro J (2009) Distribution of metals in the sediment of the Itá reservoir, Brazil. Acta Limnol Bras 21:245-250

Cunha SC, Lehotay SJ, Mastovska K, Fernandes JO, Oliveira MBPP (2007) Evaluation of the QuEChERS sample preparation approach for the analysis of pesticide residues in olives. J Sep Sci 30:620-632

EPA - Environmental Protection Agency (2009) Aquatic biodiversity. Available http://www.epa.gov/bioiweb1/aquatic/pollution.html. Accessed 10 July 2010

Gervais G, Brosillon S, Laplanchea A, Helen CJ (2008) Ultrapressure liquid chromatography electrospray tandem mass spectrometry for multiresidue determination of pesticides in water. J Chromatogr A 1202:163-172

Hajslová J, Zrostlíková J (2003) Matrix effects in (ultra)trace analysis of pesticide residues in food and biotic matrices. J Chromatogr A 1000:181-197

Hill ARC, Reynolds SL (1999) Guideline for in-house validation of analytical methods for pesticide residues in food and animal feeds. Analyst 124:953-958

Koesukwiwat U, Sanguankaew K, Leepipatpiboon N (2008) Rapid determination of phenoxy acid residues in rice by modified QuEChERS extraction and liquid chromatography-tandem mass spectrometry. Anal Chim Acta 626:10-20

Kustera M, Alda ML, Barceló D (2009) Liquid chromatographytandem mass spectrometric analysis and regulatory issues of polar pesticides in natural and treated waters. J Chromatogr A 1216:520-529

Lanças FM (2004) Validação de métodos cromatográficos de análise (Validation of chromatographic methods of analysis). Rima, São Carlos

Lehotay SJ (2005) Quick, easy, cheap, effective, rugged and safe (QuEChERS) approach for determining pesticide residues. In: Vidal JLM, Frenich AG (eds) Methods in biotechnology, vol 19. Humana Press, Totowa, p 239

Lehotay SJ, Maštovská K, Yun SJ (2005) Evaluation of two fast and easy methods for pesticide residue analysis in fatty food matrixes. J AOAC Int 88:630-638

Lesueur C, Gartner M, Mentler A, Fuerhacker M (2008) Comparison of four extraction methods for the analysis of 24 pesticides in soil samples with gas chromatography-mass spectrometry and liquid chromatography-ion trap-mass spectrometry. Talanta 75:284-293

Paschoal JAR, Rath S, Airoldi FPS, Reyes FGR (2008) Validação de métodos cromatográficos para a determinação de resíduos de medicamentos veterinários em alimentos (Validation of chromatographic methods for the determination of residues of veterinary drugs in foods). Quim Nova 31:1190-1198 
Prestes OD, Friggi CA, Adaime MB, Zanella R (2009) QuEChERSum método moderno de preparo de amostra para determinação multirresíduos de pesticidas em alimentos por métodos cromatográficos acoplados à espectrometria de massas (QuEChERS-a modern sample preparation method for pesticide multiresidue determination in food by chromatographic methods coupled to mass spectrometry). Quim Nova 32:1620-1634

Ribani M, Bottoli CBG, Collins CH, Jardim ICSF, Melo LFC (2004) Validação em métodos cromatográficos e eletroforéticos (Validation for chromatographic and electrophoretic methods). Quim Nova 27:771-780
Sanches SM, Silva CHTP, Campos SX, Vieira EM (2003) Pesticidas e seus respectivos riscos associados à contaminação da água (Pesticides and respective risks associated to water contamination). Pesticidas: R Ecotoxicole Meio Ambiente 13:53-58

Tolosa I, Readman JW, Mee LD (1996) Comparison of the performance of solid-phase extraction techniques in recovering organophophorus and organochlorine compounds from water. J Chromatogr A 725:93-106

Tundisi JG (2003) Água no século XXI: enfrentando a escassez (Water in the XXI century: facing its shortage). Rima, São Carlos 